\title{
Testosterone Protects Pancreatic $\beta$-cells from Apoptosis and Stress-Induced Accelerated Senescence
}

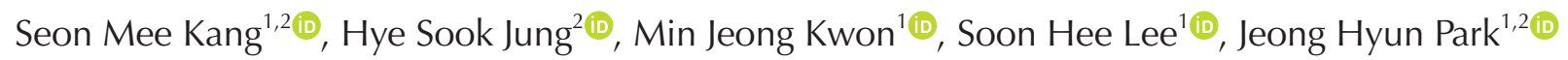 \\ ${ }^{1}$ Department of Internal Medicine, Inje University Busan Paik Hospital, College of Medicine, Inje University, ${ }^{2}$ Paik Institute for Clinical \\ Research, Inje University, Busan, Korea
}

\begin{abstract}
Purpose: Androgens are steroid hormones that are very important in the sexual development and the maintenance of male reproductive system, and also have diverse actions in non-reproductive tissues, including potent antioxidant capacity. Type 2 diabetes mellitus is caused by tissue insulin resistance and insufficient insulin secretion from the pancreatic $\beta$-cells. The progressive decline of pancreatic $\beta$-cells in diabetes is closely related with the severity of disease. We wanted to know whether dihydrotestosterone (DHT) can protect insulin secreting pancreatic $\beta$-cells from apoptosis and accelerated senescence induced by oxidative stress.

Materials and Methods: Cultured INS-1 cells were used. Various concentrations of $\mathrm{H}_{2} \mathrm{O}_{2}$ were applied to exert oxidative stresses. The degrees of apoptosis, accelerated senescence, and the changes of the expressions of related signaling molecules after the application of DHT were analyzed by CCK-8, p16 expression, SA- $\beta-G$ al staining, reverse transcription polymerase chain reactions and Western blots.

Results: The application of $\mathrm{H}_{2} \mathrm{O}_{2}$ significantly increased $(\mathrm{p}<0.05)$ the degree of senescence and apoptosis of cultured INS-1 $\beta$-cells. DHT not only showed anti-oxidant protective capacity, but also significantly reduced $(p<0.05)$ the degree of accelerated senescence.

Conclusions: DHT effectively protects pancreatic islet INS-1 $\beta$-cells from $\mathrm{H}_{2} \mathrm{O}_{2}$ induced oxidative stress.
\end{abstract}

Keywords: Aging; Apoptosis; Dihydrotestosterone; Insulin-secreting cells; Oxidative stress

This is an Open Access article distributed under the terms of the Creative Commons Attribution Non-Commercial License (http://creativecommons.org/licenses/by-nc/4.0) which permits unrestricted non-commercial use, distribution, and reproduction in any medium, provided the original work is properly cited.

\section{INTRODUCTION}

Androgens are steroid hormones that have a main role in sexual dimorphic development and maintenance of the male reproductive system [1]. Androgens are predominantly mediated by the androgen receptor, a ligand-dependent nuclear transcription factor, and a member of the steroid hormone nuclear receptor family [2]. However, a number of studies have shown that androgens have functions in non-reproductive tissues [3]. Dihydrotestosterone (DHT), an androgenic steroid hormone generated from testosterone by 5 - $\alpha$ reductase, and cannot be aromatized to estradiol. Hence, it is considered a more potent androgen than testosterone in

Received: Sep 21, 2020 Revised: Oct 6, 2020 Accepted: Oct 19, 2020 Published online Nov 16, 2020

Correspondence to: Soon Hee Lee (iD https://orcid.org/0000-0003-4776-0501

Department of Internal Medicine, Inje University Busan Paik Hospital, College of Medicine, Inje University, 75 Bokji-ro, Busanjin-gu, Busan 47392, Korea.

Tel: +82-51-890-6406, Fax: +82-51-892-0273, E-mail: 68shlee@hanmail.net 
that it binds more strongly to androgen receptors. Additionally, DHT is considered a potent antioxidant that protects against cellular damage [4].

Type 2 diabetes mellitus (T2DM) is a complex metabolic condition that increases insulin resistance combined with defective insulin secretion. The United Kingdom Prospective Diabetes Study (UKPDS) has reported a progressive deterioration in pancreatic $\beta$-cell function over time in T2DM, regardless of treatment modalities, such as diet control, insulin, sulfonylurea, or metformin [5,6]. Moreover, the insulin secretory function was found to be approximately $50 \%$ that of the normal at the time of T2DM diagnosis, as the $\beta$-cells are unable to adequately compensate for the increased metabolic demand during the prediabetic period, such as impaired fasting glucose and/or impaired glucose tolerance [5]. Defective insulin secretion leads to hyperglycemia, and consequently, can induce beta cell apoptosis and $\beta$-cell mass reduction [7]. Thus, reserving $\beta$-cell function, as well as adequate glucose control are crucial in the treatment of T2DM patients.

It is well known that testosterone deficiency promotes visceral obesity and impairs insulin sensitivity in men [8]. According to a previous population-based study, testosterone deficiency is common in male T2DM patients and may be associated with insulin resistance [9]. Furthermore, several observational studies suggest that testosterone deficiency predisposes patients to $\beta$-cell dysfunction and failure, and that testosterone replacement may improve insulin secretory function [10]. However, the molecular mechanism of testosterone action in preserving or improving $\beta$-cell function is unknown. Thus, this study was designed to investigate how DHT protects pancreatic beta cell function, using in vitro models.

\section{MATERIALS AND METHODS}

\section{INS- 1 cell culture}

INS-1 cell lines were generously provided by Dr. Won from Yeungnam University, Daegu, Korea. INS-1 cells were maintained in Roswell Park Memorial Institute medium (Sigma, St. Louis, MO, USA) containing 10\% fetal bovine serum (FBS) and $11.0 \mathrm{mM}$ glucose at $37^{\circ} \mathrm{C}$ in humidified air containing $5 \% \mathrm{CO}_{2}$. The culture medium was changed every 2 days. To create a similar senescence condition, passages between 35 and 45 of INS1 cells were used in this study.

\section{Cell proliferation assay}

To create oxidative stress and to mimic the cellular aging process, INS-1 cells were cultured with different concentrations of $\mathrm{H}_{2} \mathrm{O}_{2}$ (Sigma; 10, 20,30,40, and $50 \mu \mathrm{M})$ for 24 hours. Thereafter, the cells were treated with the Cell Counting Kit-8 (CCK-8; Dojindo, Munich, Germany) at $37^{\circ} \mathrm{C}$ for 2 hours. The optical density was measured at $450 \mathrm{~nm}$ using an automatic microplate reader (Molecular Devices, San Jose, CA, USA).

INS-1 cells were seeded in 96-well plates at a density of $1 \times 10^{4}$ cells per well and incubated for 48 hours. Following culturing in the presence of $40 \mathrm{mM} \mathrm{H}_{2} \mathrm{O}_{2}$ with DHT (Sigma) at various concentrations $(1,10$, and 100 $\mu \mathrm{M})$ for 24 hours, the media were removed and the cells were treated with the CCK- 8 at $37^{\circ} \mathrm{C}$ for 2 hours. The optical density at $450 \mathrm{~nm}$ was determined using a microplate reader.

\section{Cell death detection using labeled Annexin V}

INS-1 cells were plated in 12-well plates at a density of $4 \times 10^{5}$ cells per well and incubated in above mentioned condition. Thereafter, trypsin-ethylenediaminetetraacetic acid was added, and the cells were washed with $1 \mathrm{~mL}$ Annexin $\mathrm{V}$ binding buffer (10 mM HEPES$\mathrm{NaOH}, \mathrm{pH}$ 7.4, $150 \mathrm{mM} \mathrm{NaCl}, 5 \mathrm{mM} \mathrm{KCl}, 1 \mathrm{mM} \mathrm{MgCl}$, and $1.8 \mathrm{mM} \mathrm{CaCl}_{2}$ ) and centrifuged at 1,200 rpm for 5 minutes at $4^{\circ} \mathrm{C}$. The supernatants were removed and 3 $\mu \mathrm{L}$ of Annexin V-FITC (at a final concentration of $1 \mu \mathrm{g} /$ $\mathrm{mL}$ ) and $10 \mu \mathrm{L}$ of propidium iodide (PI) were added to each sample to identify different stages of apoptosis, or cells undergoing secondary necrosis. Following incubation for 15 minutes in the dark, $300 \mu \mathrm{L}$ of fluorescenceactivated cell sorting (FACS) buffer (1\% FBS, 0.1\% $\mathrm{NaN}_{3}$ ) was added, and cell staining was analyzed using a FACSort (BECTON DICKINSON; BD Bioscience, San Jose, CA, USA).

\section{RNA isolation and reverse transcription polymerase chain reaction}

Total cellular RNA was extracted from INS-1 cells using the TRIzol reagent (Invitrogen, Carlsbad, CA, USA). First-strand cDNA was generated by reverse transcriptase, and quantitative polymerase chain reaction (PCR) was performed using a premixed reverse transcription-PCR kit (Solgent, Daejeon, Korea). The primers used were as follows: insulin forward primer, 5'CCAGCCGCAGCCTTTGTGA-3', reverse primer, 5'GGTACAGCATTGTTCCACAATG-3'. Glyceralde- 
hyde 3-phosphate dehydrogenase forward primer, 5'GATGACCCA GATCATGTTTG-3', reverse primer, 5'-GAGCAATGATCTTGATCTTC-3'. Amplification was carried out under the following conditions using a MyCycler thermal cycler (Bio-Rad, Hercules, CA, USA): pre-denaturation at $95^{\circ} \mathrm{C}$ for 2 minutes, denaturation at $95^{\circ} \mathrm{C}$ for 30 seconds, annealing at $45^{\circ} \mathrm{C}$ for $30 \mathrm{sec}-$ onds, extension at $72^{\circ} \mathrm{C}$ for 30 seconds, and a final extension at $72^{\circ} \mathrm{C}$ for 7 minutes. Following amplification, $5 \mu \mathrm{L}$ of PCR products were subjected to electrophoresis on $1.5 \%$ agarose gels. Gels were visualized using a gel documentation system (Korea Lab Tech, Namyangju, Korea), and quantified using ImageJ software.

\section{Western blotting}

INS-1 cells were washed with phosphate-buffered saline (PBS) and lysed using mammalian tissue lysis/ extraction reagent including protease inhibitor (Roche, South San Francisco, CA, USA). Protein concentrations were determined using the BCA protein assay kit (Pierce, Rockford, IL, USA), and $1 \times$ sodium dodecyl sulfate (SDS) sample buffer (50 mM Tris pH 6.8, 2\% SDS, $10 \%$ glycerol, $50 \mathrm{mM}$ dithiothreitol, and $0.01 \%$ bromophenol blue) was added. The proteins were separated with $10 \%$ to $15 \%$ SDS-polyacrylamide gel electrophoresis, transferred onto a polyvinylidene difluoride membrane, and immunoblotted with anti-Sirt1 (Abcam, Cambridge, MA, USA), anti-phospho MAPK (Cell Signaling, Danvers, MA, USA), anti-phospho T308 Akt (Cell Signaling), anti-PARP (Cell Signaling) at $4^{\circ} \mathrm{C}$ overnight. Next, the membranes were incubated with

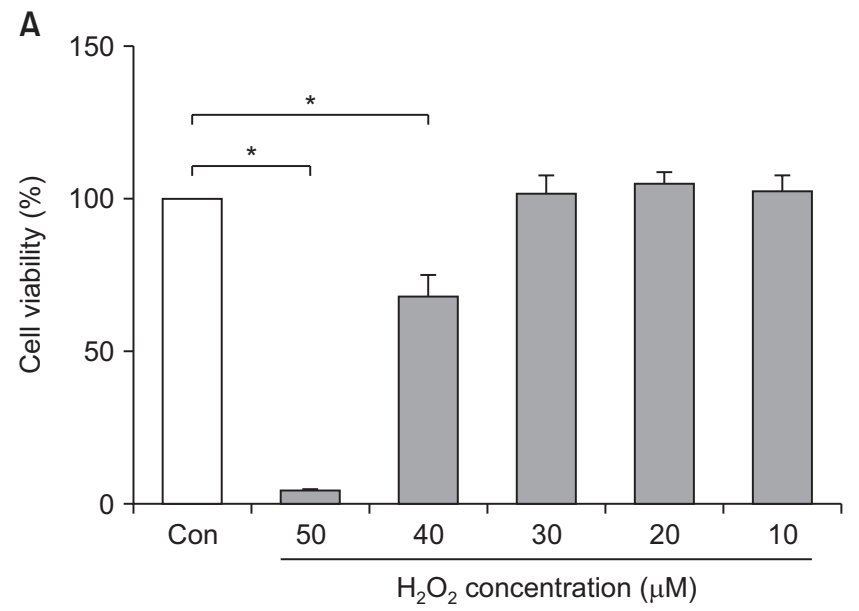

secondary antibodies (goat anti-rabbit or anti-mouse conjugated alkaline phosphatase [Cell Signaling]) for 1 hour at room temperature, and developed using an APconjugated development kit (Bio-Rad). The developed protein bands were quantified using ImageJ software.

\section{SA-beta-Gal staining}

Following incubation in appropriate conditions, INS1 cells were washed with PBS. Thereafter, the SA- $\beta$-Gal working solution ( $\mathrm{pH}$ 6.0) (Cell Signaling) was added. The cells were observed using an inverted microscope after 24 hours.

\section{Statistical analysis}

Statistical analysis was performed using IBM SPSS software (ver. 20.0; IBM Corp., Armonk, NY, USA), and data were expressed as mean \pm standard deviation. Differences between the groups of results were determined using a one-way ANOVA, followed by a Tukey's post hoc test. Statistical significance was defined as $\mathrm{p}<0.05$.

\section{RESULTS}

\section{Dihydrotestosterone restored the viability of INS- 1 cells induced by $\mathrm{H}_{2} \mathrm{O}_{2}$}

To create conditions similar to the cellular senescence process, INS-1 cells were cultured with different concentrations of $\mathrm{H}_{2} \mathrm{O}_{2}(10,20,30,40$, and $50 \mu \mathrm{M}$, respectively) for 24 hours and the CCK- 8 assay was performed. INS-1 cell viability decreased to $10 \%$ and

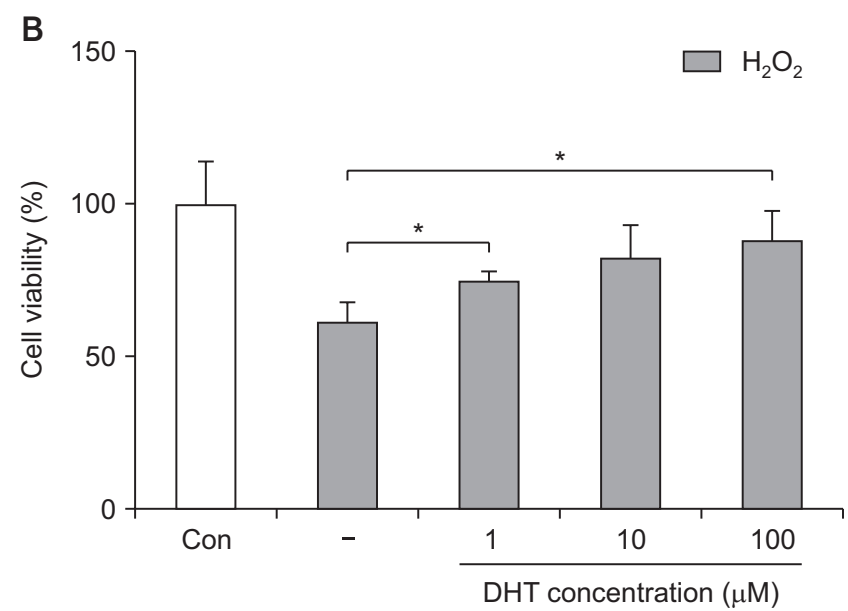

Fig. 1. Effect of $\mathrm{H}_{2} \mathrm{O}_{2}$ on INS-1 cells and the recovery of cellular viability after DHT treatment, as measured with the CCK-8 assay. (A) After treatment of $40 \mu \mathrm{M}$ of $\mathrm{H}_{2} \mathrm{O}_{2}$, the viability of INS-1 cells decreased from $100 \%$ to $65 \%$. (B) Decreased cellular viability of INS-1 cells induced by $\mathrm{H}_{2} \mathrm{O}_{2}$, can restored by DHT treatment significantly in a dose dependent manner. Con: control group, DHT: dihydrotestosterone group. *Significantly different from the control group, $\mathrm{p}<0.05$. 
$65 \%$ after treatment with $50 \mu \mathrm{M}$ and $40 \mu \mathrm{M} \mathrm{H}_{2} \mathrm{O}_{2}$, respectively (Fig. 1A). Hence, we decided to use $40 \mu \mathrm{M}$ $\mathrm{H}_{2} \mathrm{O}_{2}$ for subsequent experiments. Decreased INS-1 cell viability was significantly recovered $(\mathrm{p}<0.05)$ by DHT in a dose-dependent manner (Fig. 1B).

\section{Dihydrotestosterone attenuated cell death in INS- 1 cells induced by $\mathrm{H}_{2} \mathbf{O}_{2}$}

Additionally, to confirm the protective effect of DHT against apoptosis induced by $\mathrm{H}_{2} \mathrm{O}_{2}$, the percentage of apoptotic cells at different concentrations of DHT was detected with Annexin V-FITC and PI double staining methods (Fig. 2A). The frequency of apoptotic cells increased over 3 -fold from $5 \%$ in the control group to $17 \%$ in the $\mathrm{H}_{2} \mathrm{O}_{2}$-treatment alone group. However, INS-1 cell apoptosis induced by $\mathrm{H}_{2} \mathrm{O}_{2}$ decreased to $15 \%, 7 \%$, and $10 \%$ with 1,10 , and $100 \mu \mathrm{M}$ DHT, respectively (Fig. 2B). The percentage of apoptotic cells significantly $(\mathrm{p}<0.05)$ increased by $40 \mu \mathrm{M} \mathrm{H}_{2} \mathrm{O}_{2}$, and dose dependently reduced by DHT treatment.

\section{Dihydrotestosterone reduced pAkt and poly (ADP-ribose) polymerase expression} induced by $\mathrm{H}_{2} \mathrm{O}_{2}$

To determine the mechanism of the anti-apoptotic or cell-preserving function of DHT, we measured the expression levels of pAkt and poly (ADP-ribose) poly- merase (PARP), which play a pivotal role in cell survival under oxidative stress (Fig. 3A). pAkt expression increased 3 -fold in the $\mathrm{H}_{2} \mathrm{O}_{2}$-treatment alone group compared with the control group, and significantly decreased $(\mathrm{p}<0.05)$ with DHT treatment dose dependently. In particular, pAkt expression in the $100-\mu \mathrm{M}$ DHT group was lowered to almost the same level as that in the control group (Fig. 3B). In addition, PARP expression increased in the $\mathrm{H}_{2} \mathrm{O}_{2}$-treatment alone group and significantly decreased with DHT treatment in a dosedependent manner $(\mathrm{p}<0.05)$ (Fig. 3C).

\section{Dihydrotestosterone increased Sirtl and reduced phosphos-p38 MAPK and p16 expression induced by $\mathrm{H}_{2} \mathrm{O}_{2}$}

We evaluated the effect of DHT on the expression of Sirt1, p16, and photpho-P38 MAPK, markers related to the cellular aging process. Sirt1 expression was reduced in the $\mathrm{H}_{2} \mathrm{O}_{2}$ treatment alone group compared with the control group, and significantly increased $(p<0.05)$ with DHT treatment at both concentrations, 1 and $100 \mu \mathrm{M}$ (Fig. 4A, 4B). Phospho-p38 MAPK expression, in the DHT-treatment groups, increased with $\mathrm{H}_{2} \mathrm{O}_{2}$ treatment and reduced to almost the same level as that in the control group (Fig. 4C). The p16 expression level increased in the $\mathrm{H}_{2} \mathrm{O}_{2}$-treatment alone group compared with the control group, and significantly decreased
A

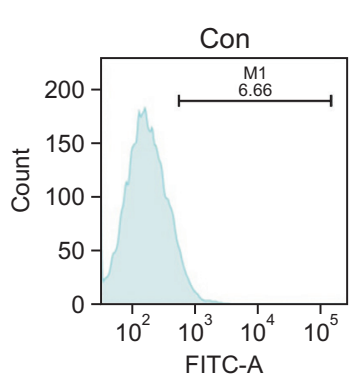

$\mathrm{H}_{2} \mathrm{O}_{2} 40 \mu \mathrm{M}$
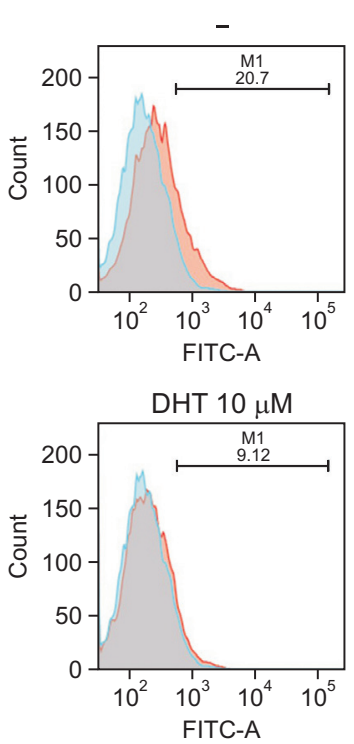
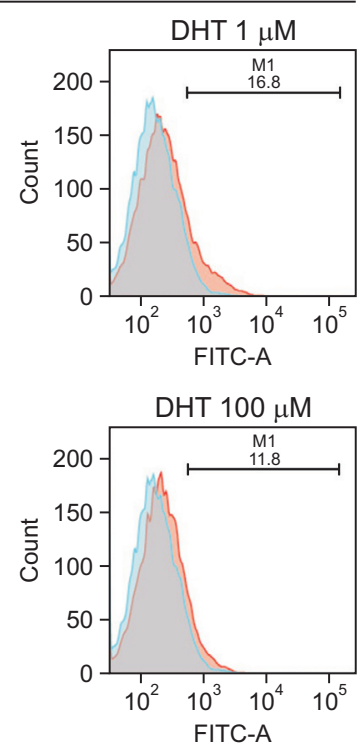

B

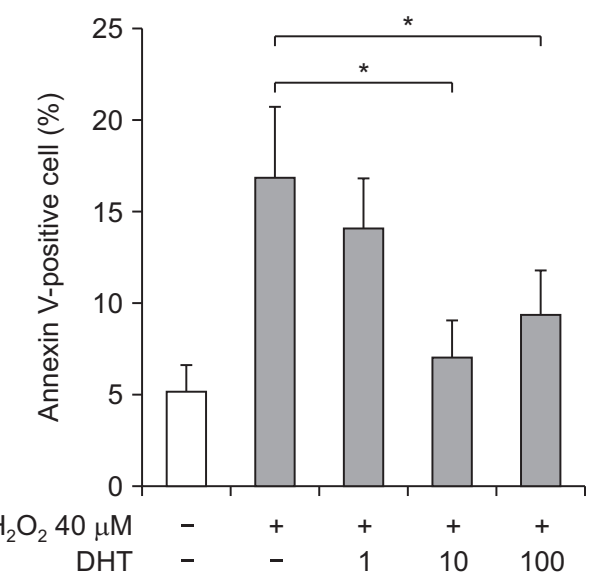

Fig. 2. (A) Cellular apoptosis of INS-1 cells was detected using Annexin V-FITC and propidium iodide double staining. (B) The proportion of Annexin V-positive cells were increased over 3-fold from control level with $\mathrm{H}_{2} \mathrm{O}_{2}$ treatment, and significantly decreased with DHT treatement. Con: control group, DHT: dihydrotestosterone group. *Significantly different from the $\mathrm{H}_{2} \mathrm{O}_{2}$ only treatment group, $\mathrm{p}<0.05$. 
A

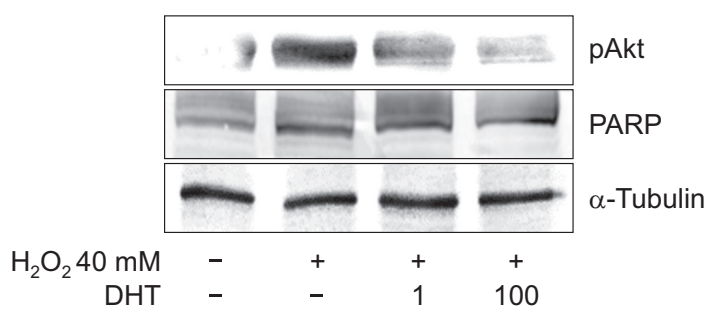

B

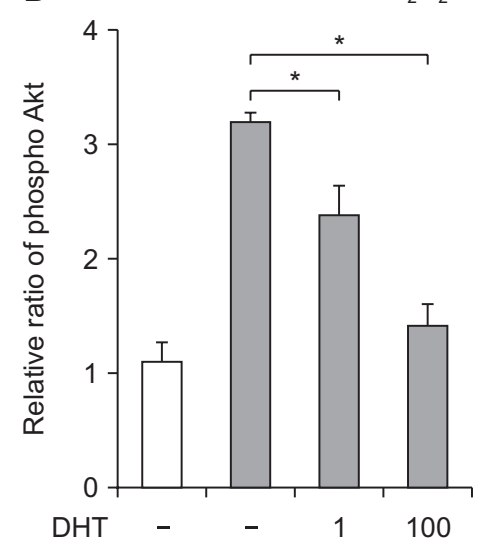

C

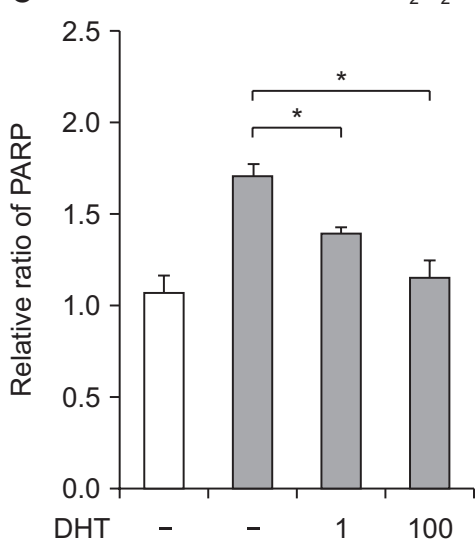

Fig. 3. DHT reduced pAkt and PARP expression of INS-1 cells induced by $\mathrm{H}_{2} \mathrm{O}_{2}$. (A) Effect of DHT treatment on the markers related to cell survival under oxidative stress. After DHT treatment, phospho Akt (B) and PARP (C) expression of INS-1 cells induced by $\mathrm{H}_{2} \mathrm{O}_{2}$ were significantly decreased. DHT: dihydrotestosterone group, Akt: protein kinase B, PARP: poly (ADP-ribose) polymerase. *Significantly different from the $\mathrm{H}_{2} \mathrm{O}_{2}$ only treatment group, $\mathrm{p}<0.05$.

A
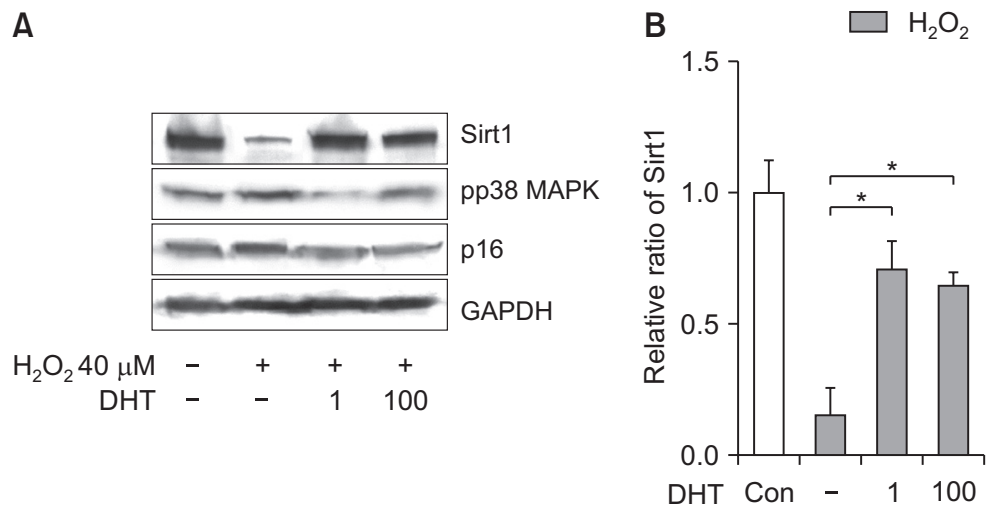

C

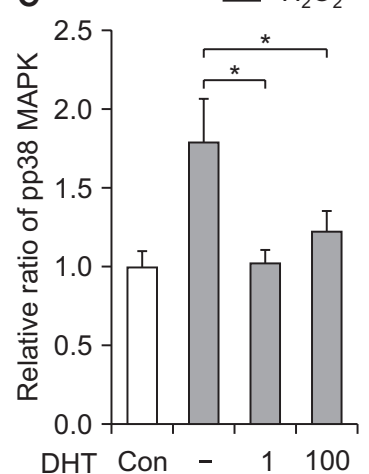

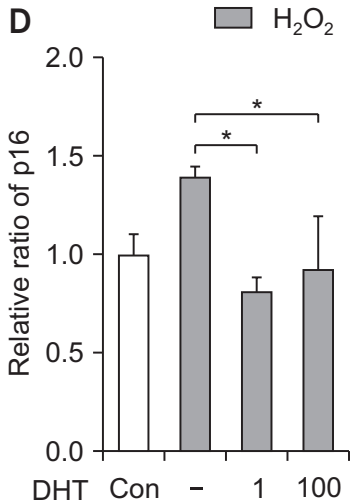

Fig. 4. (A, B) Effect of DHT treatment on the markers related to the cellular aging process. Sirt1 expression was reduced by $\mathrm{H}_{2} \mathrm{O}_{2}$ treatment, and significantly increased $(p<0.05)$ with DHT treatment. After DHT treatment, pp38 MAPK (C) and p16 (D) expression of INS-1 cells induced by $\mathrm{H}_{2} \mathrm{O}_{2}$ were significantly decreased. Sirt1: NAD-dependent deacetylase sirtuin-1, pp38: phospho-p38, MAPK: mitogen-activated protein kinase, GAPDH: glyceraldehyde 3-phosphate dehydrogenase, DHT: dihydrotestosterone group, Con: control group. ${ }^{*}$ Significantly different from the $\mathrm{H}_{2} \mathrm{O}_{2}$ only treatment group, $\mathrm{p}<0.05$.

$(\mathrm{p}<0.05)$ with DHT treatment (Fig. 4D). In addition, $\beta$-galactosidase staining was performed to elucidate the anti-aging effect of DHT on senescent INS-1 cells (Fig. 5). $\beta$-Gal $(+)$ cells significantly increased $(p<0.05)$ in the $\mathrm{H}_{2} \mathrm{O}_{2}$-treatment alone group compared with the control group, whereas it decreased in the DHT-treatment groups dose dependantly. Overall, DHT may attenuate the $\mathrm{H}_{2} \mathrm{O}_{2}$-induced accelerated senescence of INS-1 pancreatic $\beta$-cells.

\section{DISCUSSION}

According to a previous population-based study, the prevalence of hypogonadism is higher in diabetic men than in non-diabetic men. This suggests that testos- terone may be a key hormone in metabolic disease pathology, such as visceral obesity, impaired glucose control, and reduced insulin sensitivity [8,9]. Consistent with these findings, testosterone replacement therapy reduced insulin resistance and improved glycemic control in T2DM with hypogonadism [11]. Patients with prostate cancer treated with androgen deprivation therapy have primary testosterone deficiency, allowing clinical studies to evaluate the direct effect of testosterone depletion on the status of diabetes mellitus. In an observational study on 37,000 men treated for prostate cancer in the Veterans Healthcare Administration, androgen deprivation therapy with gonadotropinreleasing hormone analogs was associated with a $28 \%$ increased risk of developing diabetes compared 


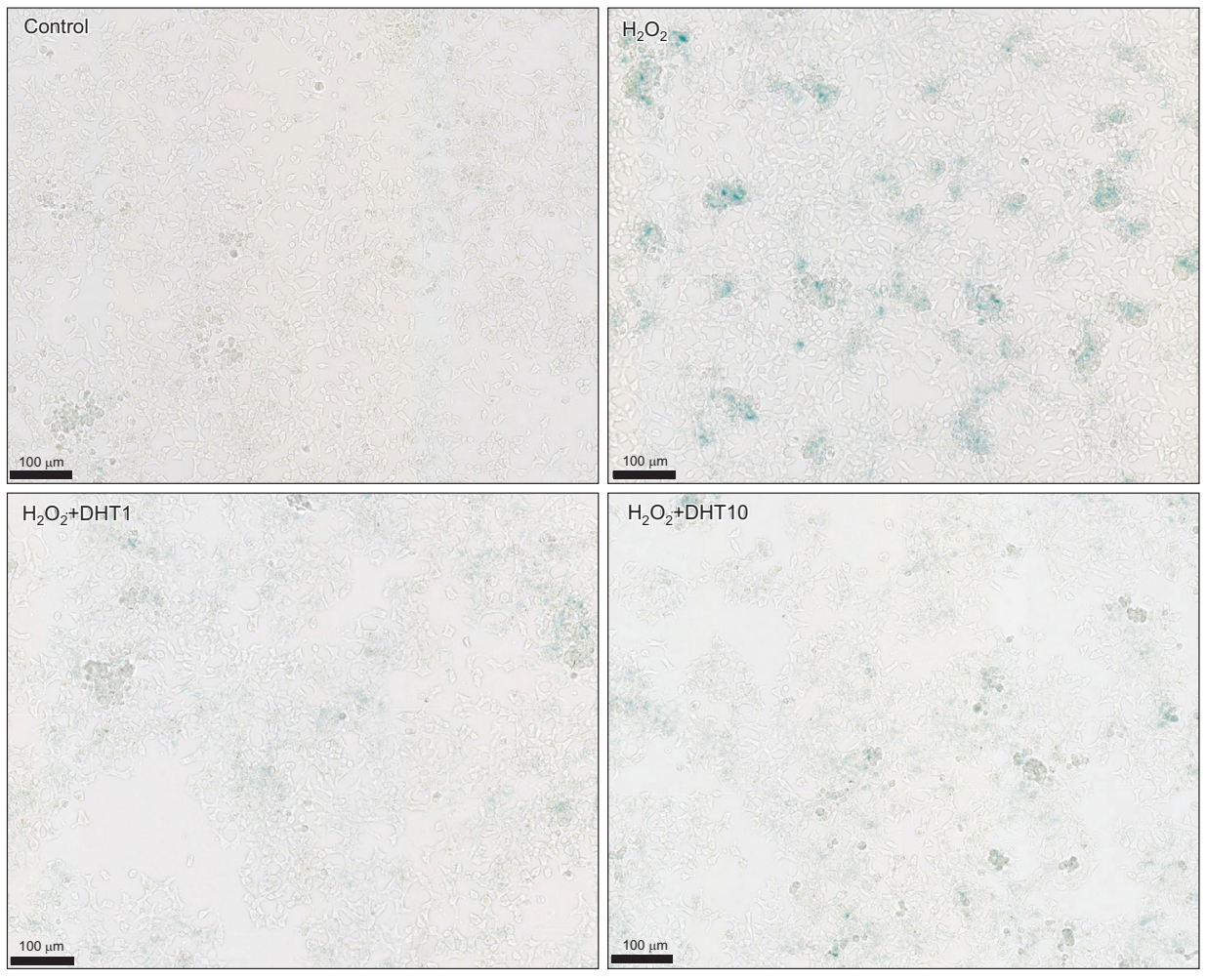

Fig. 5. Senescence associated $\beta$-galactosidase staining was done to clarify the anti-aging effect of DHT on INS-1 cells. $\beta$-Gal (+) cells increased in the $\mathrm{H}_{2} \mathrm{O}_{2}-$ treatment alone group compared with the control group, whereas it decreased in the DHT-treatment groups. DHT: dihydrotestosterone group. to prostate cancer patients treated without androgen deprivation therapy [12]. In another study, testosterone replacement therapy in obese men with secondary hypogonadism showed improved glycemic control and pancreatic $\beta$-cell function measured by HOMA-\%B [13]. Collectively, these observations suggest that testosterone deficiency not only predisposes men to insulin resistance but also causes $\beta$-cell dysfunction and failure. Testosterone replacement therapy can improve the insulin secretory function of pancreatic $\beta$-cells.

A previous study showed decreased insulin concentration, insulin receptor mRNA, and glucose oxidation in an orchiectomized rat model, and these effects were reversed after testosterone replacement [14]. Another study using a streptozotocin-induced diabetic rat model demonstrated that testosterone administration protected against pancreatic $\beta$-cell apoptosis through the induction of antioxidant enzymes [15]. Recently, it was reported that testosterone improves the differentiation efficiency of insulin-producing cells (pancreatic $\beta$-cells) of human induced pluripotent stem cells from $12 \%$ to $35 \%$, and promotes the expression of important genes associated with $\beta$-cell differentiation [15].

The anti-senescence effect of testosterone has been reported in numerous studies. The addition of testosterone can reduce the expression of several types of markers that are expressed in each step of cellular aging and apoptotic processes in in vitro models [16]. Altogether, these findings suggest that testosterone action may be necessary for pancreatic $\beta$-cell health and normal insulin secretion in men.

The incidence of T2DM has dramatically increased worldwide. Obesity, an unhealthy diet, and physical inactivity along with genetic predisposition are the main causes of this disease, which is characterized by insulin resistance in various tissues, and defects in pancreatic insulin secretion [17]. It has been well-established that intensive glycemic control is essential for preventing diabetic chronic complications, either micro- or macrovascular [5]. Unfortunately, the mean levels of blood glucose progressively deteriorate over time regardless of treatment efforts $[5,6]$. Majority of T2DM patients will show progressive loss in number and function of insulin-secreting pancreatic $\beta$-cells, and will eventually become dependent on exogenous insulin administration. Numerous factors contribute to the time-dependent decline of residual pancreatic $\beta$-cell function, including aging itself, insulin resistance leading to $\beta$-cell stress and exhaustion by persistently increased metabolic demand, direct deleterious effects of lipotoxicity, and glucolipotoxicity accompanied by excessive oxidative stress and overwhelming levels of pro-inflammatory cyto- 
kines, along with individual genetic susceptibility [18]. Pancreatic islet $\beta$-cell failure is usually progressive and inevitable in most types of T2DM, particularly after unequivocal hyperglycemia is established; this means failure of compensatory pancreatic insulin secretion to control increased metabolic demand [19]. Therefore, research efforts should not only focus on pursuing tight glycemic control, but also on factors that cause islet $\beta$-cell dysfunction and failure, and the ways to preserve mass and function of pancreatic islet $\beta$-cells.

Here, we observed that a high fraction of pancreatic $\beta$-cells showed cell death after $40 \mu \mathrm{M}$ of $\mathrm{H}_{2} \mathrm{O}_{2}$ treatment, and the addition of DHT recovered the cell viability. Moreover, in the presence of different concentrations of DHT, the proportion of apoptotic cells identified with Annexin-V labeling was significantly decreased $(p<0.05)$, especially at a concentration of 10 $\mu \mathrm{M}$. These findings are concordant with those of previous studies by Xu et al [16], in which DHT inhibited cell death and enhanced cellular viability through antioxidative effects, while DHT action was being tested on human vascular endothelial cells. It is well known that the activation of PI3 kinase and Akt phosphorylation is responsible for anti-apoptotic activities and enhancement of cell survival by DHT [20]. Our results suggest the possibility of activation of PI3 kinase signaling for anti-apoptotic effects of DHT during the $\mathrm{H}_{2} \mathrm{O}_{2}$-induced oxidative stress. Our experiments showed that $\mathrm{H}_{2} \mathrm{O}_{2}$-induced oxidative stress decreased Sirt1 expression, and increased phospho-p38 MAPK and p16 protein expression in INS-1 pancreatic $\beta$-cells, and the addition of DHT opposed senescence marker levels [21]. In addition, $\mathrm{H}_{2} \mathrm{O}_{2}$-induced oxidative stress increased the SA- $\beta$-Gal stain positivity in INS- 1 pancreatic $\beta$-cells, and the number of SA- $\beta$-Gal positive cells significantly decreased $(p<0.05)$ after DHT treatment. Cellular senescence is a natural course by which aged or damaged cells undergo cell cycle arrest and are inhibited by replication [22]. Two major pathways of cellular senescence were discovered: replicative and stress-induced [23]. In both pathways, DNA damage is triggered, which is mediated by p53, p21, and p16, leading to cell cycle arrest [24]. Once the cells undergo senescence, they exhibit morphological changes and secrete numerous proteins as part of the senescence-associated secretory phenotype (SASP), consisting of inflammatory cytokines, growth factors, and proteases [25]. SA- $\beta$-Gal is most commonly used and can highlight senescent cells with a blue dye by detecting increased $\beta$-galactosidase activity within the lysosomes of aged cells [25]. Aging, especially cellular senescence, is generally accepted as the leading risk factor for most age-related chronic diseases, such as T2DM and cardiovascular disease [26]. Targeting senescent cells, such as using senolytic agents that act against their own SASP phenomenon, has emerged as an attractive therapeutic strategy [27]. From this viewpoint, targeting senescent pancreatic $\beta$-cells represents noteworthy opportunities for advancement in the prevention and treatment of T2DM and its complications [28].

Notably, the anti-apoptotic and anti-senescent effect of DHT on pancreatic $\beta$-cells should be reserved for only male subjects in the clinical viewpoint. In clinical practice, excessive blood androgens in obese women with polycystic ovarian syndrome promotes insulin resistance and $\beta$-cell dysfunction, and eventually hyperglycemia and T2DM [29]; whereas a low androgen level in men is associated with increased risk of $\beta$-cell failure and T2DM [9]. DHT will be equally beneficial for $\beta$-cells in both sexes for apoptosis protection and accelerated senescence. However, the systemic effects of DHT would be quite different in each sex, and these differences may change the response of pancreatic $\beta$-cells to DHT in vivo. Further studies to clarify the mechanisms of different responses of pancreatic $\beta$-cells to DHT in both sexes should be conducted.

Our study has several limitations. First, only one rodent $\beta$-cell line, and not a whole islet, was used for the entire experiment. Second, DHT dose used in our experiments was not at the usual physiologic level. Indisputably, the results of our experiments could not be extrapolated to physiological conditions, and further research is warranted to determine the actual role of testosterone in pancreatic $\beta$-cell function and insulin secretion in vivo.

\section{CONCLUSIONS}

In conclusion, we showed that testosterone treatment could reduce apoptosis and the expression of senescencerelated molecular markers of INS-1 pancreatic $\beta$-cells under oxidative stress conditions. Further studies and in-depth understanding of testosterone actions in pancreatic $\beta$-cells may lead to the development of new therapeutic targets for the management of diabetes mellitus, especially in androgen deficiency and aging men. 


\section{Conflict of Interest}

The authors have nothing to disclose.

\section{Author Contribution}

Conceptualization: JHP. Data curation: SMK, HSJ, JHP. Formal analysis: SMK, HSJ, JHP. Investigation: MJK, HSJ. Methodology: HSJ. Project administration: MJK, HSJ. Supervision: JHP. Validation: SHL, JHP. Visualization: SMK, HSJ. Writing - original draft: SMK. Writing - review \& editing: SMK, SHL, JHP.

\section{Data Sharing Statement}

The data required to reproduce these findings cannot be shared at this time due to technical and time limitations.

\section{REFERENCES}

1. Murashima A, Kishigami S, Thomson A, Yamada G. Androgens and mammalian male reproductive tract development. Biochim Biophys Acta 2015;1849:163-70.

2. Heinlein CA, Chang C. Androgen receptor (AR) coregulators: an overview. Endocr Rev 2002;23:175-200.

3. Foradori CD, Weiser MJ, Handa RJ. Non-genomic actions of androgens. Front Neuroendocrinol 2008;29:169-81.

4. Lee SH, Heo JS, Lee MY, Han HJ. Effect of dihydrotestosterone on hydrogen peroxide-induced apoptosis of mouse embryonic stem cells. J Cell Physiol 2008;216:269-75.

5. Intensive blood-glucose control with sulphonylureas or insulin compared with conventional treatment and risk of complications in patients with type 2 diabetes (UKPDS 33). UK Prospective Diabetes Study (UKPDS) Group. Lancet 1998;352:837-53.

6. Effect of intensive blood-glucose control with metformin on complications in overweight patients with type 2 diabetes (UKPDS 34). UK Prospective Diabetes Study (UKPDS) Group. Lancet 1998;352:854-65.

7. Kahn SE, Zraika S, Utzschneider KM, Hull RL. The beta cell lesion in type 2 diabetes: There has to be a primary functional abnormality. Diabetologia 2009;52:1003-12.

8. Navarro G, Allard C, Xu W, Mauvais-Jarvis F. The role of androgens in metabolism, obesity, and diabetes in males and females. Obesity (Silver Spring) 2015;23:713-9.

9. Grossmann M, Gianatti EJ, Zajac JD. Testosterone and type 2 diabetes. Curr Opin Endocrinol Diabetes Obes 2010;17:24756.
10. Inaba M, Otani Y, Nishimura K, Takaha N, Okuyama A, Koga $\mathrm{M}$, et al. Marked hyperglycemia after androgen-deprivation therapy for prostate cancer and usefulness of pioglitazone for its treatment. Metabolism 2005;54:55-9.

11. Jones TH, Arver S, Behre HM, Buvat J, Meuleman E, Moncada I, et al.; TIMES2 Investigators. Testosterone replacement in hypogonadal men with type 2 diabetes and/or metabolic syndrome (the TIMES2 study). Diabetes Care 2011;34:82837.

12. Keating NL, O'Malley AJ, Freedland SJ, Smith MR. Diabetes and cardiovascular disease during androgen deprivation therapy: observational study of veterans with prostate cancer. J Natl Cancer Inst 2010;102:39-46.

13. Navarro G, Xu W, Jacobson DA, Wicksteed B, Allard C, Zhang G, et al. Extranuclear actions of the androgen receptor enhance glucose-stimulated insulin secretion in the male. Cell Metab 2016;23:837-51.

14. Muthusamy T, Dhevika S, Murugesan P, Balasubramanian K. Testosterone deficiency impairs glucose oxidation through defective insulin and its receptor gene expression in target tissues of adult male rats. Life Sci 2007;81:534-42.

15. Palomar-Morales M, Morimoto S, Mendoza-Rodríguez CA, Cerbón MA. The protective effect of testosterone on streptozotocin-induced apoptosis in beta cells is sex specific. Pancreas 2010;39:193-200.

16. Xu ZR, Hu L, Cheng LF, Qian Y, Yang YM. Dihydrotestosterone protects human vascular endothelial cells from $\mathrm{H}(2)$ $\mathrm{O}(2)$-induced apoptosis through inhibition of caspase-3, caspase-9 and p38 MAPK. Eur J Pharmacol 2010;643:254-9.

17. DeFronzo RA, Ferrannini E, Groop L, Henry RR, Herman WH, Holst JJ, et al. Type 2 diabetes mellitus. Nat Rev Dis Primers 2015;1:15019.

18. Prentki M, Nolan CJ. Islet beta cell failure in type 2 diabetes. J Clin Invest 2006;116:1802-12.

19. Poitout V, Robertson RP. Minireview: secondary beta-cell failure in type 2 diabetes--a convergence of glucotoxicity and lipotoxicity. Endocrinology 2002;143:339-42.

20. Tuttle RL, Gill NS, Pugh W, Lee JP, Koeberlein B, Furth EE, et al. Regulation of pancreatic beta-cell growth and survival by the serine/threonine protein kinase Akt1/PKBalpha. Nat Med 2001;7:1133-7.

21. Cuadrado A, Nebreda AR. Mechanisms and functions of p38 MAPK signalling. Biochem J 2010;429:403-17.

22. Campisi J. Cellular senescence as a tumor-suppressor mechanism. Trends Cell Biol 2001;11:S27-31.

23. Herranz N, Gil J. Mechanisms and functions of cellular senescence. J Clin Invest 2018;128:1238-46.

24. Stein GH, Drullinger LF, Soulard A, Dulić V. Differential 
roles for cyclin-dependent kinase inhibitors p21 and p16 in the mechanisms of senescence and differentiation in human fibroblasts. Mol Cell Biol 1999;19:2109-17.

25. Debacq-Chainiaux F, Erusalimsky JD, Campisi J, Toussaint O. Protocols to detect senescence-associated beta-galactosidase (SA-betagal) activity, a biomarker of senescent cells in culture and in vivo. Nat Protoc 2009;4:1798-806.

26. Khosla S, Farr JN, Tchkonia T, Kirkland JL. The role of cellular senescence in ageing and endocrine disease. Nat Rev Endocrinol 2020;16:263-275.
27. Tchkonia T, Kirkland JL. Aging, cell senescence, and chronic disease: emerging therapeutic strategies. JAMA 2018;320:1319-20.

28. Palmer AK, Tchkonia T, LeBrasseur NK, Chini EN, Xu M, Kirkland JL. Cellular senescence in type 2 diabetes: a therapeutic opportunity. Diabetes 2015;64:2289-98.

29. Rubin KH, Glintborg D, Nybo M, Abrahamsen B, Andersen $M$. Development and risk factors of type 2 diabetes in a nationwide population of women with polycystic ovary syndrome. J Clin Endocrinol Metab 2017;102:3848-57. 